\title{
Kinetic modelling of lactic acid production from whey by Lactobacillus casei (NRRL B-441)
}

\author{
Duygu Altıok, Figen Tokatı* and Şebnem Harsa \\ Food Engineering Department, Izmir Institute of Technology, Izmir 35430, Turkey
}

\begin{abstract}
The biomass growth, lactic acid production and lactose utilisation kinetics of lactic acid production from whey by Lactobacillus casei was studied. Batch fermentation experiments were performed at controlled pH and temperature with six different initial whey lactose concentrations $\left(9-77 \mathrm{~g} \mathrm{dm}^{-3}\right)$ in a $3 \mathrm{dm}^{3}$ working volume bioreactor. Biomass growth was well described by the logistic equation with a product inhibition term. In addition, biomass and product inhibition effects were defined with corresponding power terms, which enabled adjustment of the model for low- and high-substrate conditions. The Luedeking-Piret equation defined the product formation kinetics. Substrate consumption was explained by production rate and maintenance requirements. A maximum productivity of $2.5 \mathrm{~g} \mathrm{dm}^{-3} \mathrm{~h}^{-1}$ was attained with an initial lactose concentration of $35.5 \mathrm{~g} \mathrm{dm}^{-3}$.

(C) 2006 Society of Chemical Industry
\end{abstract}

Keywords: lactic acid; kinetic model; Lactobacillus casei; whey

\section{NOTATION}

$f \quad$ toxic power for biomass inhibition

$h \quad$ toxic power for product inhibition

$K_{\mathrm{S}} \quad$ Monod constant (g lactose $\mathrm{dm}^{-3}$ )

$m_{\mathrm{S}}$ maintenance coefficient ( $\mathrm{g}$ lactose $\mathrm{g}^{-1}$ biomass $\mathrm{h}^{-1}$ )

$N \quad$ number of observations

$P \quad$ lactic acid concentration $\left(\mathrm{g} \mathrm{dm}^{-3}\right)$

$P_{\mathrm{f}} \quad$ final lactic acid concentration $\left(\mathrm{g} \mathrm{dm}^{-3}\right)$

$P_{\mathrm{m}}$ inhibitory lactic acid concentration $\left(\mathrm{g} \mathrm{dm}^{-3}\right)$

$P_{0} \quad$ initial lactic acid concentration $\left(\mathrm{g} \mathrm{dm}^{-3}\right)$

$q_{\mathrm{P}} \quad$ specific production rate (g lactic acid $\mathrm{g}^{-1}$ biomass $\mathrm{h}^{-1}$ )

$S \quad$ substrate concentration $\left(\mathrm{g} \mathrm{dm}^{-3}\right)$

$S_{\mathrm{f}} \quad$ final substrate concentration $\left(\mathrm{g} \mathrm{dm}^{-3}\right)$

$S_{0} \quad$ initial substrate concentration $\left(\mathrm{g} \mathrm{dm}^{-3}\right)$

SSE sum of squares of errors

$X$ biomass concentration $\left(\mathrm{g} \mathrm{dm}^{-3}\right)$

$X_{\mathrm{m}}$ inhibitory biomass concentration $\left(\mathrm{g} \mathrm{dm}^{-3}\right)$

$X_{\max }$ maximum biomass concentration at stationary phase $\left(\mathrm{g} \mathrm{dm}^{-3}\right)$

$X_{0} \quad$ initial biomass concentration $\left(\mathrm{g} \mathrm{dm}^{-3}\right)$

$Y_{\text {PS }}$ product yield coefficient (g lactic acid $\mathrm{g}^{-1}$ lactose)

$Y_{\mathrm{XS}}$ biomass yield coefficient ( $\mathrm{g}$ biomass $\mathrm{g}^{-1}$ lactose)

$t \quad$ time $(\mathrm{h})$

$\alpha \quad$ growth-associated product formation coefficient (g lactic acid $\mathrm{g}^{-1}$ biomass)

$\beta \quad$ non-growth-associated product formation coefficient (g lactic acid $\mathrm{g}$ biomass ${ }^{-1} \mathrm{~h}^{-1}$ )

$\mu \quad$ specific growth rate $\left(\mathrm{h}^{-1}\right)$

$\mu_{\max }$ maximum specific growth rate $\left(\mathrm{h}^{-1}\right)$

\section{INTRODUCTION}

Lactic acid, which is mostly used in the pharmaceutical, cosmetic, chemical, textile and food industries, exists in two optically active forms, $\mathrm{D}(-)$ and $\mathrm{L}(+)$. Lactic acid is produced by chemical synthesis, by hydrolysis of lactonitrile and by microbial fermentation processes. ${ }^{1} \mathrm{~L}(+)$-Lactic acid is the preferred isomer, since it is involved in normal human metabolism, but chemical synthesis yields only racemic (DL)-lactic acid. On the other hand, L(+)-lactic acid can be produced by fermentation processes. The homofermentative Lactobacillus casei, which is a Gram-positive and facultative anaerobe, is known to be an L(+)-lactic acid producer. ${ }^{2}$

Among many carbohydrate materials used for the production of lactic acid, whey lactose deserves special consideration. Whey, a by-product of the cheese-making process, is an abundant food-grade material and a potential environmental pollutant owing to its high lactose content. ${ }^{3}$ Since whey contains complex nutrients for bacteria and is cheap, it might be a good source for microbial lactic acid production.

Kinetic models have been used to predict the effects of operating parameters on biomass growth, substrate utilisation and product formation rates and also in the optimisation of fermentation processes. Many different unstructured models involving microbial growth, substrate utilisation and product formation have been applied to experimental data. The kinetic models have been based on the Monod equation and the logistic equation for microbial growth and the Luedeking-Piret equation for product formation. ${ }^{4}$

* Correspondence to: Figen Tokatlı, Food Engineering Department, İzmir Institute of Technology, Urla, İzmir 35430, Turkey

E-mail: figentokatli@iyte.edu.tr

(Received 29 June 2005; revised version received 11 November 2005; accepted 2 December 2005)

Published online 23 May 2006; DOI: 10.1002/jctb.1512 
Modified forms of the Monod and logistic equations have been applied to indicate the effects of biomass, product and substrate inhibition on biomass growth for lactic acid production. Models including terms for both substrate and product inhibition have been suggested as well as models considering only product inhibition. $^{5-8}$ In the study by $\mathrm{Fu}$ and Mathews, ${ }^{9}$ model parameters such as specific growth rate and the Monod constant were expressed as a function of $\mathrm{pH}$. So far, kinetic modelling studies with L. casei have been mostly conducted with substrates other than whey. Some of the models have been generated for continuous production. There have been studies on the kinetic analysis of $L$. case $i$ mainly with glucose as carbon source. Models of growth and lactic acid production in batch cultures of $L$. case $i$ from glucose have been proposed by considering the nutrient compounds as factors in a number of designed experiments using response surface methodology. ${ }^{10}$ Kinetic models of $L$. casei in continuous fermentation systems with product inhibition and glucose as substrate have also been assessed. ${ }^{11,12}$ Another study investigated L. casei kinetics considering both product and substrate inhibition in a continuous membrane bioreactor with glucose as carbon source. ${ }^{13}$ Previous studies together with the kinetic parameters for different lactic acid bacteria and substrates are listed in Table 1.

The present study was aimed at investigating the kinetics of $L$. casei for batch production of $\mathrm{L}(+)$ lactic acid using whey as carbon source. Owing to its homofermentative character, the use of $L$. casei is advantageous with this cheap carbon source for lactic acid production. Batch fermentations were performed at constant $\mathrm{pH}$ and temperature and with various initial lactose concentrations. Based on the experimental data, rate expressions of biomass growth, product formation and substrate utilisation were developed with biomass and product inhibition terms in the logistic equation. Prior to the final parameter optimisation study, response surface methodology (RSM) was used to assess the importance of the model parameters on the model fit and to find a range for their numerical values to use in the simulations.

\section{MATERIALS AND METHODS Micro-organism}

The micro-organism used in this study, L. casei NRRL B-441, was obtained from the US Department of Agriculture, National Centre for Agricultural Utilization Research (Peoria, IL, USA). The microorganism was supplied in lyophilised form, activated in $10 \%(\mathrm{w} / \mathrm{v})$ sterilised litmus milk (Difco, Detroit, $\mathrm{MI}$, USA) propagation medium and maintained at $4{ }^{\circ} \mathrm{C}$.

\section{Media}

Whey powder containing approximately $70 \%$ lactose and $11.5 \%$ protein (P1nar Dairy Products, Inc., Izmir, Turkey) was used as carbon source. Whey from the same production batch was used throughout. It was dissolved to attain the desired initial substrate concentration $\left(S_{0}\right)$. Before use, protein precipitation was induced by heating the whey solution at $121^{\circ} \mathrm{C}$ for $15 \mathrm{~min}$. Precipitated proteins were removed by centrifugation (Sigma, Osterode, Germany) at $3835 \times g$ for $20 \mathrm{~min}$. The supernatant was used as substrate for the fermentations. The basic media for fermentations consisted of $\left(\mathrm{dm}^{-3}\right.$ deionised water $)$

Table 1. Previous kinetic modelling studies including lactic acid bacteria

\begin{tabular}{|c|c|c|c|c|c|c|c|c|}
\hline Micro-organism & Substrate & $\mu_{\max }$ & $K_{S}$ & $\alpha$ & $\beta$ & $m_{\mathrm{S}}$ & $Y_{X S}$ & $Y_{\mathrm{PS}}$ \\
\hline L. casei (this work) & Whey lactose & 0.265 & 0.72 & $\begin{aligned} \alpha & =0.029 S_{0} \\
& +2.686\end{aligned}$ & 0.06 & 0.03 & $\begin{aligned} Y_{X S}= & -0.0017 S_{0} \\
& +0.24\end{aligned}$ & 0.682 \\
\hline L. helveticus ${ }^{8}$ & Whey lactose & 0.25 & 0.9 & 4.6 & 0.23 & 2.65 & 0.064 & 0.61 \\
\hline L. lactis $^{14}$ & Lactose & 1.1 & 1.32 & 0.932 & 3.02 & - & - & 0.93 \\
\hline L. case $i^{10}$ & Glucose & 0.994 & - & 1.332 & 0.035 & - & 0.409 & 0.834 \\
\hline L. curvatus $^{15}$ & Glucose & - & - & - & - & - & 0.23 & 1 \\
\hline L. helveticus ${ }^{16}$ & Whey lactose & 0.7 & 0.22 & - & - & - & - & - \\
\hline L. helveticus ${ }^{17}$ & Whey lactose & 0.82 & 0.22 & 4.5 & 1.62 & - & - & 0.95 \\
\hline L. helveticus ${ }^{18}$ & Whey lactose & 0.49 & - & 2.56 & 0.76 & - & - & 0.84 \\
\hline L. rhamnosus ${ }^{19}$ & Glucose & 0.633 & 0.3 & 6.6 & 0.33 & - & 1 & 1 \\
\hline L. bulgaricus ${ }^{20}$ & Lactose & 1.14 & 3.36 & - & - & - & 0.10 & 0.90 \\
\hline L. plantarum 9 & Lactose & 0.364 & 44.4 & - & - & - & - & 1.02 \\
\hline L. helveticus ${ }^{21}$ & Whey lactose & - & - & 4.26 & 0.5 & - & - & - \\
\hline L. helveticus ${ }^{22}$ & Whey lactose & 0.21 & - & - & - & - & 0.08 & 0.71 \\
\hline L. lactis ${ }^{5}$ & Glucose & 0.403 & 0.79 & 13.2 & 0.0645 & - & - & - \\
\hline L. helveticus ${ }^{23}$ & Whey lactose & 0.76 & - & 2.69 & 0.71 & - & - & - \\
\hline L. delbrueckii ${ }^{7}$ & $\begin{array}{l}\text { Sucrose from beet } \\
\text { molasses }\end{array}$ & 0.831 & - & 0.235 & 0.087 & - & 0.27 & 0.91 \\
\hline L. casei ${ }^{11}$ & Glucose & 1.23 & 0.203 & - & - & - & 0.115 & 0.977 \\
\hline L. delbrueckii 6 & Glucose & 0.0696 & 0.0967 & 0.3853 & 0.0032 & 0.00014 & - & - \\
\hline L. helveticus ${ }^{4}$ & Glucose & - & - & 2.2 & 0.55 & - & - & - \\
\hline
\end{tabular}


10 g yeast extract, $0.5 \mathrm{~g} \mathrm{KH}_{2} \mathrm{PO}_{4}, 0.5 \mathrm{~g} \mathrm{~K}_{2} \mathrm{HPO}_{4}, 0.2 \mathrm{~g}$ $\mathrm{MgSO}_{4}, 0.05 \mathrm{~g} \mathrm{MnSO}_{4} \cdot \mathrm{H}_{2} \mathrm{O}$ and varying amounts of lactose.

\section{Fermentation conditions}

Batch fermentation experiments were performed in a $5 \mathrm{dm}^{3}$ bioreactor (Bioengineering ALF, Wald, Switzerland) with a working volume of $3 \mathrm{dm}^{3}$. The batch bioreactor was equipped with $\mathrm{pH}$, temperature and stirrer speed controllers. Fermentation runs were conducted at atmospheric pressure and constant temperature $\left(37^{\circ} \mathrm{C}\right), \mathrm{pH}(5.5)$ and agitation $(200 \mathrm{rpm})$ based on the findings of a previous study. ${ }^{24}$ The $\mathrm{pH}$ value was maintained by automatic addition of 10 mol dm ${ }^{-3} \mathrm{NaOH}$. The bioreactor and fermentation media were sterilised in an autoclave at $121^{\circ} \mathrm{C}$ for $15 \mathrm{~min}$. The bioreactor was inoculated with $375 \mathrm{~cm}^{3}$ of 24 -h-old seed culture $(12.5 \% \mathrm{v} / \mathrm{v})$. The seed culture was grown batchwise in $250 \mathrm{~cm}^{3}$ flasks with $100 \mathrm{~cm}^{3}$ working volume in a temperature-controlled incubator shaker (Lab-Line, Dubuque, IA, USA) operated at $150 \mathrm{rpm}$ and $37^{\circ} \mathrm{C}$. Sterile $\mathrm{CaCO}_{3}(3 \mathrm{~g})$ was added to the fermentation medium in each flask to neutralise the acid formed during the fermentations. After the addition of $\mathrm{CaCO}_{3}, 5 \mathrm{~cm}^{3}$ of litmus milk culture which had been incubated at $37^{\circ} \mathrm{C}$ for $24 \mathrm{~h}$ was inoculated. Batch fermentations with six different initial concentrations of whey lactose varying between 9.0 and $77.1 \mathrm{~g} \mathrm{dm}^{-3}$ were run randomly.

\section{Analytical techniques}

Total biomass concentration was determined by optical density measurements (Cary 100, Varian Palo Alto, CA, USA) at $610 \mathrm{~nm}\left(\mathrm{OD}_{610}\right)$, which were converted to cell dry weight $(X)$ using a calibration curve. At each sampling time, $\sim 10 \mathrm{~cm}^{3}$ of sample was taken and centrifuged at $1610 \times g$ for $15 \mathrm{~min}$ in a Hettich (Tuttlingen, Germany) EBA 12R centrifuge. Lactose and lactic acid concentrations were analysed in a high-performance liquid chromatography (HPLC) system (Perkin Elmer, Boston, MA, USA) with an Aminex HPX-87H column (Biorad Laboratories, Hercules, CA, USA) operated at $45^{\circ} \mathrm{C}$ with a MetaTherm column oven (Metachem, Lake Forest, CA, USA). As eluent, $5 \mathrm{mmol} \mathrm{dm}^{-3} \mathrm{H}_{2} \mathrm{SO}_{4}$ was used at a flow rate of $0.6 \mathrm{~cm}^{3} \mathrm{~min}^{-1}$. The standard deviation range of biomass measurements for six fermentation runs was $0.0235-0.075 \mathrm{~g} \mathrm{dm}^{-3}$. The standard deviation for lactic acid measurements by HPLC varied between 0.52 and $1.15 \mathrm{~g} \mathrm{dm}^{-3}$. A similar range of $0.93-1.14 \mathrm{~g} \mathrm{dm}^{-3}$ was observed for lactose measurements.

\section{Parameter estimation}

The kinetic model was based on the rate equations of biomass growth, product formation and substrate utilisation to describe the fermentation process. Three ordinary differential equations were solved simultaneously by the Runga-Kutta method. Differences between model predictions and experimental data of batch fermentations were minimised according to the sum of squares of errors (SSE) of the model fit:

$$
\begin{aligned}
\mathrm{SSE}= & \sum_{i=1}^{N}\left[\left(\frac{X_{i \exp }-X_{i \mathrm{cal}}}{X_{\max }}\right)^{2}+\left(\frac{P_{i \exp }-P_{i \mathrm{cal}}}{P_{\max }}\right)^{2}\right. \\
& \left.+\left(\frac{S_{i \exp }-S_{i \mathrm{cal}}}{S_{\max }}\right)^{2}\right]
\end{aligned}
$$

where $X_{\max }, P_{\max }$ and $S_{\max }$ are the maximum observations of the relevant measurements and subscripts 'exp' and 'cal' denote experimental and calculated values respectively. Some of the kinetic parameters in the rate equations were determined according to the objective function given in Eqn (1). The significance of the kinetic terms on minimising SSE was assessed by RSM with experimental design software MODDE 7 (Umetrics AB, Umeå, Sweden). A Box-Behnken design resulting in 57 runs, including one central run, was used with seven kinetic parameters as factors $\left(\alpha, \beta, f, h, m_{\mathrm{S}}, X_{\mathrm{m}}\right.$ and $\left.P_{\mathrm{m}}\right)$. SSE, which is the result of simulations by the kinetic equation set, was the response variable. For each fermentation run, computer simulations were done at 57 different factor combinations and SSE values were reported. At the end of the analysis the most significant factors on minimising SSE were found in descending order as $f, \alpha, h, X_{\mathrm{m}}, P_{\mathrm{m}}, \beta$ and $m_{\mathrm{S}}$.

\section{MODEL DEVELOPMENT Growth kinetics}

The widely used Monod equation relates the specific growth rate $(\mu)$ and an essential compound concentration $(S)$ and is given by

$$
\mu=\frac{\mu_{\max } S}{K_{\mathrm{S}}+S}
$$

where $\mu_{\max }$ is the maximum achievable growth rate when $S \gg K_{\mathrm{S}}$ and the concentrations of all other essential nutrients are not limiting; $K_{\mathrm{S}}$ is known as the Monod constant. Under optimal growth conditions and when the inhibitory effect of substrate and product plays no role, the rate of cell growth follows the wellknown exponential relationship

$$
\frac{\mathrm{d} X}{\mathrm{~d} t}=\frac{\mu_{\max } S}{K_{\mathrm{S}}+S} X
$$

Equation (3) implies that $X$ increases with time regardless of substrate availability. In reality the growth of cells is governed by a hyperbolic relationship and there is a limit to the maximum attainable cell mass concentration. In order to describe such growth kinetics with both exponential and stationary phases, the logistic equation is introduced:

$$
\frac{\mathrm{d} X}{\mathrm{~d} t}=\mu X\left(1-\frac{X}{X_{\mathrm{m}}}\right)
$$


where $X_{\mathrm{m}}$ is the stationary population size, or upper biomass concentration, above which bacteria do not grow.

Moreover, other forms of the Monod equation can be utilised to account for different inhibition effects. For the product inhibition effect, Levenspiel proposed the following simple generalisation of the Monod equation: ${ }^{25}$

$$
\frac{\mathrm{d} X}{\mathrm{~d} t}=\mu X\left(1-\frac{P}{P_{\mathrm{m}}}\right)^{h}
$$

where $P_{\mathrm{m}}$ is the maximum product concentration above which bacteria do not grow and $h$ is the toxic power, which characterises the manner in which the upper concentration limit is approached for the inhibitory product $P_{\mathrm{m}}$. The inhibition effect increases with increasing toxic power $h$. With a similar power term $f$ for the biomass inhibition effect, the final modified form of the logistic equation can be stated as

$$
\frac{\mathrm{d} X}{\mathrm{~d} t}=\mu\left(1-\frac{X}{X_{\mathrm{m}}}\right)^{f}\left(1-\frac{P}{P_{\mathrm{m}}}\right)^{h}
$$

\section{Lactic acid production}

Product formation is described by Luedeking-Piret kinetics. The product formation rate depends on both the instantaneous biomass concentration $X$ and growth rate $\mathrm{d} X / \mathrm{d} t$ in a linear fashion:

$$
\frac{\mathrm{d} P}{\mathrm{~d} t}=\alpha \frac{\mathrm{d} X}{\mathrm{~d} t}+\beta X
$$

where $\alpha$ and $\beta$ are empirical constants that possibly vary with fermentation conditions.

\section{Lactose utilisation}

The substrate utilisation kinetics may be expressed as substrate conversion to product and substrate consumption for maintenance:

$$
\frac{\mathrm{d} S}{\mathrm{~d} t}=-\frac{1}{Y_{\mathrm{PS}}} \frac{\mathrm{d} P}{\mathrm{~d} t}-m_{\mathrm{S}} X
$$

where $Y_{\mathrm{PS}}$ is the product yield coefficient and $m_{\mathrm{S}}$ is the maintenance coefficient.

\section{RESULTS AND DISCUSSION \\ Determination of kinetic parameters}

Batch production of lactic acid was performed at six different lactose concentrations in order to determine the kinetic parameters of the rate equations. Lactobacillus casei, whose media requirements and growth conditions were determined by a previous study in the same laboratory conditions, ${ }^{24}$ was selected
Table 2. Experimental and calculated $\alpha$ values

\begin{tabular}{lll}
\hline$S_{0}\left(\mathrm{~g} \mathrm{dm}^{-3}\right)$ & $\alpha_{\text {exp }}$ & $\alpha_{\text {cal }}$ \\
\hline 9.0 & 3.30 & 3.0 \\
21.4 & 3.61 & 3.3 \\
35.5 & 3.67 & 3.7 \\
48.1 & 4.42 & 4.0 \\
61.2 & 4.39 & 4.4 \\
77.1 & 5.31 & 5.0 \\
\hline
\end{tabular}

because it is a homofermentative bacterium of $\mathrm{L}(+)-$ lactic acid.

The experimental $\alpha$ values $\left(\alpha_{\exp }\right)$ in Table 2 represent the growth-associated term parameter in the Luedeking-Piret equation. According to a study of Amrane and Prigent, ${ }^{23} \alpha$ can be calculated by using the experimental lactic acid and biomass concentration data in the following equation:

$$
P-P_{0}=\alpha\left(X-X_{0}\right)
$$

The results showed that there was a positive linear relationship between $\alpha_{\exp }$ and the initial lactose concentration $\left(S_{0}\right): \alpha_{\exp }=0.029 S_{0}+2.911 \quad\left(R^{2}=\right.$ 0.955).

In the model development of the six fermentation data sets, decisions on whether the values of model parameters should be changed or kept constant were made by means of the RSM analysis of SSE. It was seen that $f, h$ and $\alpha$ are the most significant factors in minimising the SSE values of simulations. However, $f$ and $h$ did not change over a wide range. Their values can be fixed at 0.5 for all fermentation runs except those at low and high $S_{0}$ values. For $9.0 \mathrm{~g} \mathrm{dm}^{-3}$ initial whey lactose the $f$ and $h$ values were determined as 0.1 and 0.3 respectively, showing a lower grade of inhibition by biomass and product. For $77.1 \mathrm{~g} \mathrm{dm}^{-3}$ initial whey lactose the $f$ and $h$ values were determined as 0.7 and 0.5 respectively. This increase in $f$ value shows a greater biomass inhibition effect in the case of increased substrate concentration. On the other hand, $\alpha$ shows great variability depending on the initial substrate concentration. For this reason, in the optimisation part of the study, only the $\alpha$ values were changed in the simulations, while the other six parameters were kept constant. In the first attempt the $\alpha_{\exp }$ values were input to the Luedeking-Piret equation. Then the best $\alpha$ value ( $\alpha_{\text {cal }}$ ) for each data set was investigated by minimising the objective function (1). A positive linear relation between $\alpha_{\mathrm{cal}}$ and the initial substrate concentration $\left(S_{0}\right)$ was also observed $\left(R^{2}=0.993\right)$. The closeness between experimental and calculated values was noted (Table 2). The maximum specific growth rate $\left(\mu_{\max }\right)$ and $K_{\mathrm{S}}$ were calculated as $0.265 \mathrm{~h}^{-1}$ and $0.72 \mathrm{~g} \mathrm{dm}^{-3}$ respectively from the experimental data of specific growth rate and initial substrate concentration. The average value for product yield on substrate, $Y_{\mathrm{PS}}$, was taken as 0.682 in the model development. A decrease in the value of biomass yield, $Y_{\mathrm{XS}}$, was observed with 
increasing initial lactose concentration. This negative relationship, explained by a linear equation (Table 1), yields relatively low values of $Y_{\mathrm{XS}}$ when compared with $Y_{\mathrm{PS}}$ values.

\section{Growth kinetics}

Examination of the experimental data revealed that the Monod kinetic model was not applicable to this fermentation system. The Monod equation defines the biomass growth rate as an exponential relationship. The logistic equation, on the other hand, describes such growth kinetics in terms of both exponential and stationary phases. In addition, the effect of product inhibition is considerable for lactic acid fermentation. The influx of lactic acid present in the culture medium causes dissipation of the proton gradient that is maintained across the cell membrane. The bacteria require maintenance energy to regulate this $\mathrm{pH}$ gradient. If the energy becomes insufficient, the growth of bacteria stops because of product inhibition. Therefore the modification of the logistic equation with a product inhibition term, based on the generalised form of the Monod equation by Levenspiel, gave better agreement of model predictions with experimental data. The logistic equation was also modified with different forms of substrate inhibition. The Haldane equation $\left(\mu=\mu_{\max } S /\left(K_{\mathrm{S}}+S+S^{2} / K_{\mathrm{i}}\right)\right.$, where $K_{\mathrm{i}}$ is the substrate inhibition constant) and exponential substrate inhibition $\left(\mu=\mu_{\max }\left[S /\left(K_{\mathrm{S}}+S\right)\right] \exp \left(-S / K_{\mathrm{i}}\right)\right)$ models were used. ${ }^{5,25}$ However, the models with a substrate inhibition term did not produce good predictions with the experimental data.

The logistic equation modified with biomass and product inhibition terms produced lower values of SSE. The use of Eqn (6) is more applicable to the wide range of initial substrate concentration fermentations, since the toxic powers define the power of the inhibition and vary for extreme cases such as very low and very high initial substrate concentrations, where the inhibition effects become negligible and significant respectively. As $f$ and $h$ values increase, the change in biomass concentration with time $(\mathrm{d} X / \mathrm{d} t)$ decreases. This corresponds to a decrease in growth due to the increase in the inhibitory effect of product and biomass. Good correlations were achieved between model outputs and experimental data. The simulation results are shown in Figs 1-6 for 9.0, 21.4, 35.5, 48.1, 61.2 and $77.1 \mathrm{~g} \mathrm{dm}^{-3}$ initial substrate concentrations respectively.

\section{Lactic acid production kinetics}

The lactic acid kinetics was explained by Eqn (7). Lactic acid production took place not only in the growth phase but also in the stationary phase, though in lower amount, as can be seen especially in Figs 2-6. The lactic acid production mostly took place in the exponential growth of $L$. casei. In order to show this, the percentage of growth-associated lactic acid production $(\% P$-assoc) for each fermentation $\left(S_{0}\right.$ in $\left.\mathrm{g} \mathrm{dm}^{-3}\right)$ was calculated via the formula

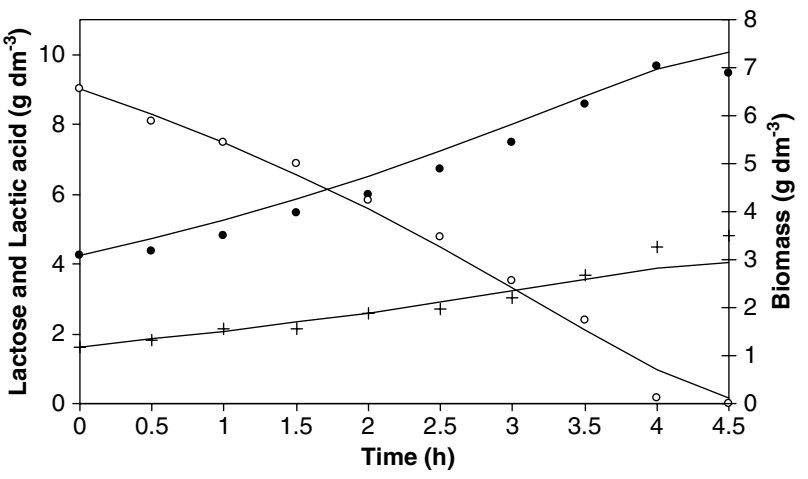

Figure 1. Model (- $\longrightarrow$ ) and experimental (+, biomass concentration; 0 , product formation; $O$, substrate utilisation) data for $9.0 \mathrm{~g} \mathrm{dm}^{-3}$ initial substrate concentration.

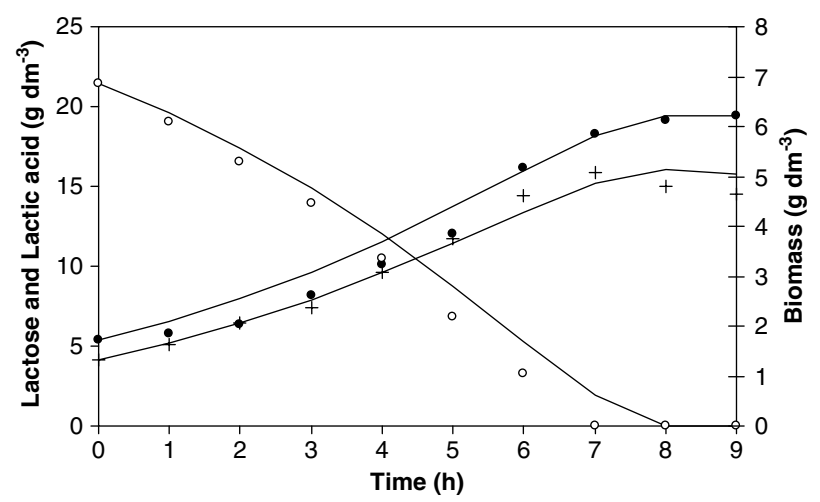

Figure 2. Model (-) and experimental (+, biomass concentration; $\bullet$, product formation; $O$, substrate utilisation) data for $21.4 \mathrm{~g} \mathrm{dm}^{-3}$ initial substrate concentration.

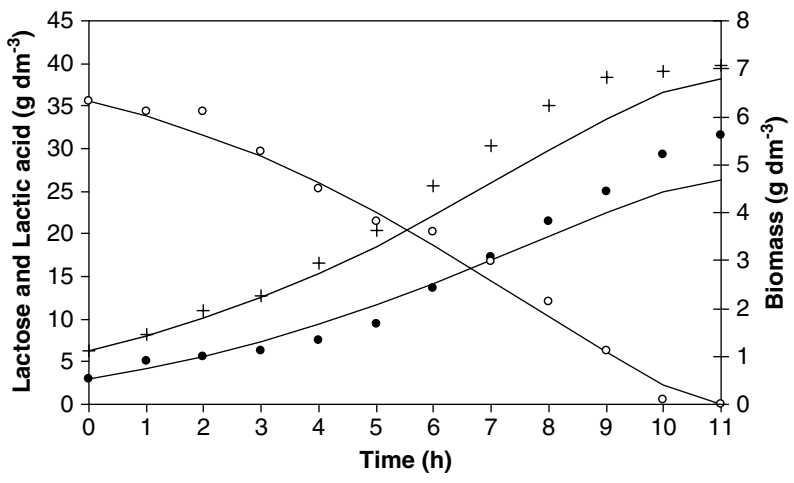

Figure 3. Model (-) and experimental (+, biomass concentration; 0 , product formation; $O$, substrate utilisation) data for $35.5 \mathrm{~g} \mathrm{dm}^{-3}$ initial substrate concentration.

$100\left(P-P_{\mathrm{o}}\right) /\left(P_{\max }-P_{\mathrm{o}}\right): \% P$-assoc $=100$ for $S_{0}=$ $9.0 ; \% P$-assoc $=92.17$ for $S_{0}=21.4 ; \% P$-assoc $=$ 77.04 for $S_{0}=35.5 ; \% P$-assoc $=75.96$ for $S_{0}=$ $48.1 ; \% P$-assoc $=71.27$ for $S_{0}=61.2 ; \% P$-assoc $=$ 74.01 for $S_{0}=77.1$. The modified Luedeking-Piret equation which was used to define lactic acid production by Lactobacillus helveticus ${ }^{26}$ was also used to fit the experimental data:

$$
\frac{\mathrm{d} P}{\mathrm{~d} t}=\alpha \frac{\mathrm{d} X}{\mathrm{~d} t}+\beta X\left(1-\frac{S_{\mathrm{res}}}{S}\right)
$$




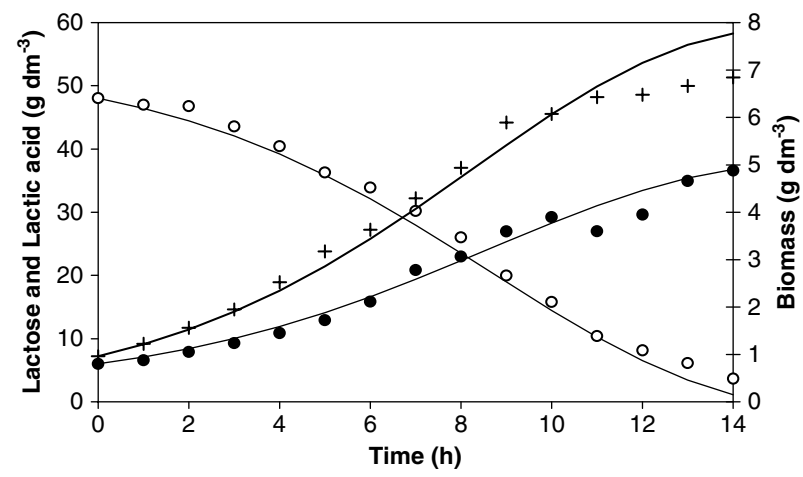

Figure 4. Model (—) and experimental (+, biomass concentration; $\bullet$, product formation; $\bigcirc$, substrate utilisation) data for $48.1 \mathrm{~g} \mathrm{dm}^{-3}$ initial substrate concentration.

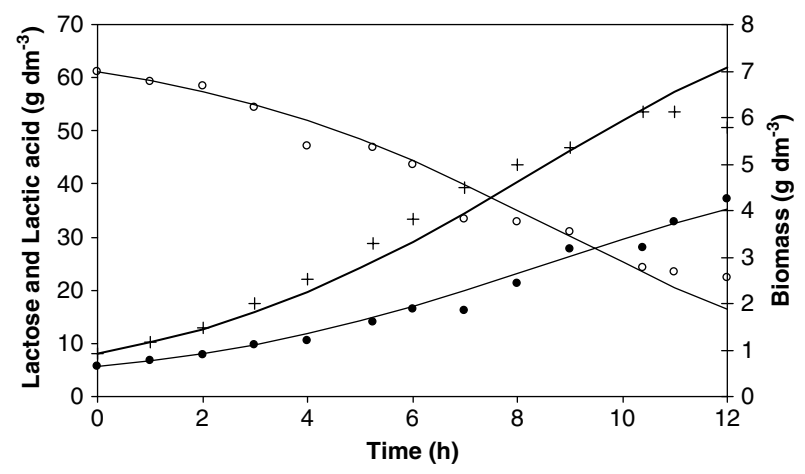

Figure 5. Model (- $\longrightarrow$ ) and experimental ( + , biomass concentration; 9 , product formation; $O$, substrate utilisation) data for $61.2 \mathrm{~g} \mathrm{dm}^{-3}$ initial substrate concentration.

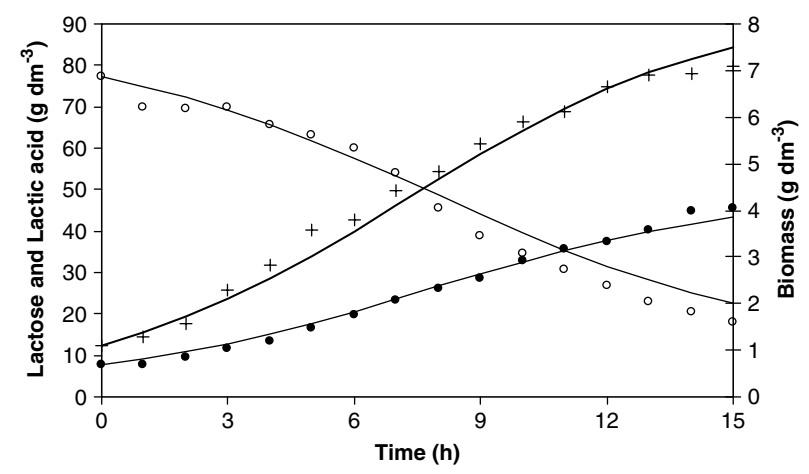

Figure 6. Model (- $\longrightarrow$ ) and experimental ( + , biomass concentration; $\bullet$, product formation; $O$, substrate utilisation) data for $77.1 \mathrm{~g} \mathrm{dm}^{-3}$ initial substrate concentration. where $S_{\text {res }}$ is the lactose concentration at the end of the batch. For the initial lactose concentrations of 9.0, 21.4 and $35.5 \mathrm{~g} \mathrm{dm}^{-3}, S_{\text {res }}=0$. Then the modified form turns into Eqn (7) automatically. For the initial lactose concentrations of 48.1 and $61.2 \mathrm{~g} \mathrm{dm}^{-3}$, Eqn (10) did not make any change in terms of the minimisation of SSE and $R^{2}$ values. For $S_{0}=$ $77.1 \mathrm{~g} \mathrm{dm}^{-3}$, SSE with Eqn (10) was obtained as 0.100 , which is higher than the previous results (see Table 4). The modified Luedeking-Piret equation did not give any improved results for the fermentation experiments.

\section{Lactose consumption kinetics}

The substrate utilisation, in a general sense, may be expressed as

$$
\frac{\mathrm{d} S}{\mathrm{~d} t}=-\frac{1}{Y_{\mathrm{XS}}} \frac{\mathrm{d} X}{\mathrm{~d} t}-\frac{1}{Y_{\mathrm{PS}}} \frac{\mathrm{d} P}{\mathrm{~d} t}-m_{\mathrm{S}} X
$$

Very high values of SSE (range 1.61-3.02) were obtained when Eqn (11) was used with the experimental data. A sudden depletion in substrate concentration, caused by a very small value of $Y_{\mathrm{XS}}$, predicted neither biomass nor product to reach actual values. The equation for substrate utilisation rate was changed by considering both substrate conversion to product and substrate consumption for maintenance of biomass growth. The substrate utilisation kinetics given by Eqn (8) was also used in the study of Dutta et $a l .{ }^{6}$ It may be presumed that a certain amount of substrate is used for maintenance of cells during fermentation in order to perform normal metabolic activity irrespective of growth. The $m_{\mathrm{S}}$ value was changed between 0.0015 and $0.03 \mathrm{~g} \mathrm{~g}^{-1} \mathrm{~h}^{-1}$ in the simulations. According to the statistical analysis of response surface data, it was concluded that $m_{\mathrm{S}}$ was an insignificant parameter in the minimisation of SSE. In all fermentations an $m_{\mathrm{S}}$ value of $0.03 \mathrm{~g} \mathrm{~g}^{-1} \mathrm{~h}^{-1}$ gave slightly lower SSE values. Table 3 summarises the results of RSM analysis in terms of the $p$ values of the parameters. A low $p$ value $(p<0.1$ significance level) shows that the parameter is very significant in the minimisation of SSE.

Similarly, the magnitudes of $\beta, f, h, X_{\mathrm{m}}$ and $P_{\mathrm{m}}$ were defined by examining the results of the response surface study. The model parameters $\alpha, f$ and $h$ are presented in Table 4 along with the SSE values and

Table 3. Results of RSM: $p$ values of parameters in minimisation study of SSE

\begin{tabular}{|c|c|c|c|c|c|c|}
\hline$S_{0}\left(\mathrm{~g} \mathrm{dm}^{-3}\right)$ Parameter & 9.0 & 21.4 & 35.5 & 48.1 & 61.2 & 77.1 \\
\hline$\alpha$ & 0 & 0 & 0 & 0.0742 & 0.0099 & $7.1 \times 10^{-15}$ \\
\hline$\beta$ & $3.5 \times 10^{-6}$ & $1.4 \times 10^{-13}$ & $5.5 \times 10^{-10}$ & $0.3985^{*}$ & $0.1870 *$ & 0.0022 \\
\hline$f$ & 0 & 0 & 0 & $4.9 \times 10^{-13}$ & $4.1 \times 10^{-11}$ & $1.0 \times 10^{-18}$ \\
\hline$h$ & 0 & 0 & 0 & $4.9 \times 10^{-8}$ & $7.2 \times 10^{-7}$ & $5.2 \times 10^{-13}$ \\
\hline$m_{\mathrm{S}}$ & 0.0010 & $2.2 \times 10^{-8}$ & $0.1062 *$ & $0.2572^{*}$ & $0.6734^{*}$ & $0.1360^{*}$ \\
\hline$X_{m}$ & $3.5 \times 10^{-15}$ & 0 & 0 & $5.7 \times 10^{-8}$ & $1.7 \times 10^{-5}$ & $1.3 \times 10^{-12}$ \\
\hline$P_{\mathrm{m}}$ & $3.7 \times 10^{-7}$ & $1.4 \times 10^{-14}$ & $1.4 \times 10^{-15}$ & 0.0005 & 0.0010 & $3.2 \times 10^{-9}$ \\
\hline
\end{tabular}

* Insignificant parameter $(p>0.1)$. 
Table 4. Model parameters, SSE values and coefficient of determination for different fermentation runs

\begin{tabular}{lllllllll}
\hline & & & & & \multicolumn{4}{c}{$R^{2}$} \\
\cline { 6 - 8 } $\begin{array}{c}S_{0} \\
\left(\mathrm{~g} \mathrm{dm}^{-3}\right)\end{array}$ & & & & & & & \\
\cline { 5 - 8 } cal & $f$ & $h$ & SSE & Biomass & Product & Substrate \\
\hline 9.0 & 3.0 & 0.1 & 0.3 & 0.080 & 0.947 & 0.986 & 0.990 \\
21.4 & 3.3 & 0.5 & 0.5 & 0.080 & 0.976 & 0.985 & 0.990 \\
35.5 & 3.7 & 0.5 & 0.5 & 0.148 & 0.989 & 0.977 & 0.989 \\
48.1 & 4.0 & 0.5 & 0.5 & 0.105 & 0.977 & 0.978 & 0.997 \\
61.2 & 4.4 & 0.5 & 0.5 & 0.130 & 0.951 & 0.982 & 0.961 \\
77.1 & 5.0 & 0.7 & 0.5 & 0.069 & 0.989 & 0.996 & 0.989 \\
\hline
\end{tabular}

the correlation coefficients $\left(R^{2}\right)$ for biomass, product (lactic acid) and substrate (lactose) using the model defined by Eqns (6)-(8). The kinetic parameters $\beta, X_{\mathrm{m}}$ and $P_{\mathrm{m}}$ were determined as $0.06,8$ and 90 respectively.

\section{Productivity of fermentation runs}

A better explanation for productivity can be achieved by complete substrate utilisation. However, in this study, not all fermentations lasted until all the substrate was consumed. Thus the product concentrations when the substrate concentration was zero were predicted by model simulations. According to the predicted values of final product concentration, the plot of predicted productivity versus initial substrate concentration is shown in Fig. 7. A maximum productivity of $2.5 \mathrm{~g} \mathrm{dm}^{-3} \mathrm{~h}^{-1}$ was achieved in the fermentation with $35.5 \mathrm{~g} \mathrm{dm}^{-3}$ initial substrate concentration. Maximum conversion of substrate to product was also achieved in that fermentation. The productivity values are comparable to the results achieved in previously published studies. The productivity for the same lactic acid bacteria was found as $2.2 \mathrm{~g} \mathrm{dm}^{-3} \mathrm{~h}^{-1}$ in a medium containing $10 \mathrm{~g} \mathrm{dm}^{-3}$ yeast extract and $64 \mathrm{~g} \mathrm{dm}^{-3}$ whey lactose under the same fermentation conditions. ${ }^{24}$ Another study reported different productivity values for $L$. case $i$ NRRL B-441 at $37^{\circ} \mathrm{C}: 5.6 \mathrm{~g} \mathrm{dm}^{-3} \mathrm{~h}^{-1}$ with glucose and $1.5 \mathrm{~g} \mathrm{dm}^{-3} \mathrm{~h}^{-1}$ with barley flour. ${ }^{27}$ The maximum productivity value obtained was less than the productivity value that would have been achieved with glucose, as expected. However, the treatment of whey in such fermentation systems would be advantageous,

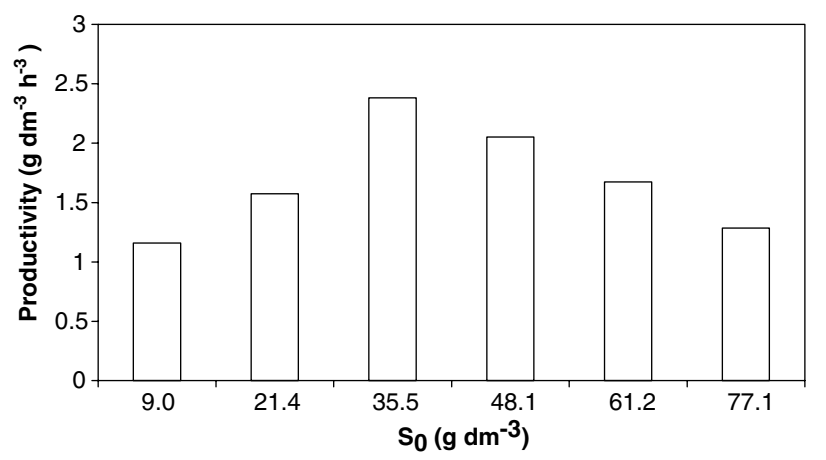

Figure 7. Productivity values at six different initial concentrations of whey lactose. since it provides a complex nutritional environment for the bacteria. After a peak at $S_{0}=35.5 \mathrm{~g} \mathrm{dm}^{-3}$ the decrease in productivity values can be explained by the lactic acid and biomass inhibition effects as the kinetic model of biomass growth suggests.

\section{CONCLUSION}

The batch fermentation of whey lactose by L. casei to produce lactic acid, which is a widely used organic acid, was modelled by kinetic equations of biomass growth, product formation and substrate consumption. The equation for specific growth rate was modified by including biomass and product inhibition terms. The magnitudes of toxic powers of the inhibition terms expressed the degree of inhibition by both biomass and lactic acid on production. This biomass growth model was considered advantageous since the inhibition effect could be adjusted by changing the toxic powers, which made the model applicable for most of the fermentations. Another useful part of the model is that the growthrelated constant $\alpha$ in the Luedeking-Piret equation was determined as a function of initial whey lactose concentration. In this study, no substrate inhibition was observed within the experimental range of whey lactose concentrations. The substrate utilisation rate equation was based on the substrate utilised for product formation and maintenance. A maximum productivity of $2.5 \mathrm{~g} \mathrm{dm}^{-3} \mathrm{~h}^{-1}$ was attained at $35.5 \mathrm{~g} \mathrm{dm}^{-3}$ initial lactose concentration, confirming the results of similar studies. The investigation of kinetic parameters by RSM was found to be very useful for deciding on the important factors in the optimisation part of the study.

\section{REFERENCES}

1 Vick Roy TB, Lactic acid, in Comprehensive Biotechnology, Vol. 3, ed. by Moo-Young M. Pergamon, Oxford, pp. 761-776 (1985).

2 Vaccari G, Gonzales-Vara A, Campi AL, Dosi E, Brigidi P and Matteuzzi D, Fermentative production of L-lactic acid by Lactobacillus casei DSM 20011 and product recovery using ion exchange resins. Appl Microbiol Biotechnol 40:23-27 (1993).

3 Roukas T and Kotzekidou P, Lactic acid production from deproteinized whey by mixed cultures of free and coimmobilized Lactobacillus casei and Lactococcus lactis cells using fedbatch culture. Enzyme Microb Technol 22:199-204 (1998).

4 Luedeking $\mathrm{R}$ and Piret EL, A kinetic study of the lactic acid fermentation. Batch process at controlled $\mathrm{pH}$. $\mathcal{F}$ Biochem Microbiol Technol Eng 4:393-412 (1959).

5 Akerberg C, Hofvendahl K, Zacchi G and Hahn-Hägerdal B, Modelling the influence of $\mathrm{pH}$, temperature, glucose and lactic acid concentrations on the kinetics of lactic acid production by Lactococcus lactis ssp. lactis ATCC 19435 in whole-wheat flour. Appl Microbiol Biotechnol 49:682-690 (1998).

6 Dutta SK, Mukherjee A and Chakraborty P, Effect of product inhibition on lactic acid fermentation: simulation and modelling. Appl Microbiol Biotechnol 46:410-413 (1996).

7 Montreagudo JM, Rodriguez L, Rincon J and Fuertes J, Kinetics of lactic acid fermentation by Lactobacillus delbrueckii grown on beet molasses. F Chem Technol Biotechnol 68:271-276 (1997). 
8 Biazar J, Tango M, Babolian E and Islam R, Solution of the kinetic modelling of lactic acid fermentation using Adomian decomposition method. Appl Math Comput 144:433-439 (2003).

$9 \mathrm{Fu} \mathrm{W}$ and Mathews AP, Lactic acid production from lactose by Lactobacillus plantarum: kinetic model and effects of $\mathrm{pH}$, substrate, and oxygen. Biochem Eng f 3:163-170 (1999).

$10 \mathrm{Ha}$ MY, Kim SW, Lee YW, Kim MJ and Kim SJ, Kinetics analysis of growth and lactic acid production in $\mathrm{pH}$ controlled batch cultures of Lactobacillus casei $\mathrm{KH}-1$ using yeast extract/corn steep liquor/glucose medium. F Biosci Bioeng 96:134-140 (2003).

11 Pinelli D, Gonzalez-Vara A, Matteuzzi D and Magelli F, Assessment of kinetic models for the production of L- and D-lactic acid isomers by Lactobacillus casei DMS 20011 and Lactobacillus coryniformis DMS 20004 in continuous fermentation. f Ferment Bioeng 83:209-212 (1997).

12 Gonzalez-Vara A, Vaccari G, Dosi E, Trilli A, Rossi M and Matteuzzi D, Enhanced production of $\mathrm{L}(+)$ lactic acid in chemostat by Lactobacillus casei DSM 20011 using ionexchange resins and cross-flow filtration in a fully automated pilot plant controlled via NIR. Biotechnol Bioeng 67:147-156 (2000).

13 Boudrant J, Menshutina NV, Skorohodov AV, Guseva EV and Fick M, Mathematical modelling of cell suspension in high cell density conditions: application to L-lactic acid fermentation using Lactobacillus case $i$ in membrane bioreactor. Process Biochem 40:1641-1647 (2005).

14 Boonmee M, Leksawasdi N, Bridge W and Rogers PL, Batch and continuous culture of Lactococcus lactis NZ133: experimental data and model development. Biochem Eng $\mathcal{f}$ 14:127-135 (2003).

15 Messens W, Verluyten J, Leroy F and Vuyst LD, Modelling growth and bacteriocin production by Lactobacillus curvatus LTH 1174 in response to temperature and $\mathrm{pH}$ values used for European sausage fermentation processes. Int $\mathcal{F}$ Food Microbiol 81:41-52 (2002)

16 Schepers AW, Thibauld J and Lacroix C, Lactobacillus helveticus growth and lactic acid production during $\mathrm{pH}$-controlled batch cultures in whey permeate/yeast extract medium. Part I. Multiple factor kinetic analysis. Enzyme Microb Technol 30:176-186 (2002).
17 Schepers AW, Thibauld J and Lacroix C, Lactobacillus helveticus growth and lactic acid production during $\mathrm{pH}$-controlled batch cultures in whey permeate/yeast extract medium. Part II. Kinetic modelling and model validation. Enzyme Microb Technol 30:187-194 (2002).

18 Amrane A, Batch cultures of supplemented whey permeate using Lactobacillus helveticus: unstructured model for biomass formation, substrate consumption and lactic acid production. Enzyme Microb Technol 28:827-834 (2001).

19 Kwon S, Yoo I, Lee WG, Chang HN and Chang YK, Highrate continuous production of lactic acid by Lactobacillus rhamnosus in a two-stage membrane cell-recycle bioreactor. Biotechnol Bioeng 73:25-34 (2001).

20 Burgos-Rubio CN, Okas MR and Wankat PC, Kinetic study of the conversion of different substrates to lactic acid using Lactobacillus bulgaricus. Biotechnol Prog 16:305-314 (2000).

21 Kulozik U and Wilde J, Rapid lactic acid production at high cell concentrations in whey ultrafiltrate by Lactobacillus helveticus. Enzyme Microb Technol 24:297-302 (1999).

22 Tango MSA and Ghaly AE, Effect of temperature on lactic acid production from cheese whey using Lactobacillus helveticus under batch conditions. Biomass Bioenerg 16:61-78 (1999).

23 Amrane A and Prigent Y, Growth and lactic acid production coupling for Lactobacillus helveticus cultivated on supplemented whey: influence of peptidic nitrogen deficiency. $\mathcal{F}$ Biotechnol 55:1-8 (1997).

24 Büyükkileci AO and Harsa $S$, Batch production of $\mathrm{L}(+)$ lactic acid from whey by Lactobacillus casei NRRL B-441. I Chem Technol Biotechnol 79:1036-1040 (2004).

25 Velizarov S and Beschkov V, Biotransformation of glucose to free gluconic acid by Gluconobacter oxydans: substrate and product inhibition situations. Process Biochem 33:527-534 (1998).

26 Amrane A, Analysis of the kinetics of growth and lactic acid production for Lactobacillus helveticus growing on supplemented whey permeate. $\mathcal{f}$ Chem Technol Biotechnol 80:345-352 (2005).

27 Hofvendahl $\mathrm{K}$ and Hahn-Hägerdal B, Factors affecting the fermentative lactic acid production from renewable resources. Enzyme Microb Technol 26:87-107 (2000). 